\title{
Next-Generation Sequencing Identifies Polyunsaturated Fatty Acid Responsive Genes in the Juvenile Rat Cerebellum
}

\author{
Aaron A. Mehus ${ }^{1, *}$, Aaron M. Dickey ${ }^{2}$, Timothy P. L. Smith ${ }^{2}{ }^{-0}$, Kathleen M. Yeater ${ }^{3}$ and \\ Matthew J. Picklo ${ }^{1}$ \\ 1 USDA-ARS Grand Forks Human Nutrition Research Center, Grand Forks, ND 58203, USA; \\ Matthew.Picklo@ARS.USDA.GOV \\ 2 USDA-ARS U.S. Meat Animal Research Center, Clay Center, NE 68933, USA; \\ Aaron.Dickey@ARS.USDA.GOV (A.M.D.); Tim.Smith@ARS.USDA.GOV (T.P.L.S.) \\ 3 USDA-ARS, Plains Area, Fort Collins, CO 80526, USA; Kathleen.Yeater@ARS.USDA.GOV \\ * Correspondence: Aaron.Mehus@ARS.USDA.GOV; Tel.: +1-701-795-8152
}

Received: 20 December 2018; Accepted: 7 February 2019; Published: 15 February 2019

\begin{abstract}
Dietary $n-3$ polyunsaturated fatty acids (PUFA) influence postnatal brain growth and development. However, little data exist regarding the impacts of dietary $n-3$ PUFA in juvenile animals post weaning, which is a time of rapid growth. We tested the hypothesis that depleting dietary n-3 PUFA would result in modifications to the cerebellar transcriptome of juvenile rats. To test this hypothesis, three week old male rats (an age that roughly corresponds to an 11 month old child in brain development) were fed diets containing either soybean oil (SO) providing $1.1 \%$ energy from $\alpha$-linolenic acid (ALA; 18:3n-3; ALA-sufficient) or corn oil (CO) providing $0.13 \%$ energy from ALA (ALA-deficient) for four weeks. Fatty acids (FAs) in the cerebellum were analyzed and revealed a 4-fold increase in n-6 docosapentaenoic acid (DPA; 22:5n-6), increases in arachidonic acid (AA; 20:4n-6) and docosatetraenoic acid (DTA; 22:4n-6), but no decrease in docosahexaenoic acid (DHA; 22:6n-3), in animals fed CO versus SO. Transcript abundance was then characterized to identify differentially expressed genes (DEGs) between the two diets. Upper quartile (UQ) scaling and transcripts per million (TPM) data normalization identified 100 and 107 DEGs, respectively. Comparison of DEGs from the two normalization methods identified 70 genes that overlapped, with $90 \%$ having abundance differences less than 2-fold. Nr4a3, a transcriptional activator that plays roles in neuroprotection and learning, was elevated over 2-fold from the CO diet. These data indicate that expression of $\mathrm{Nr} 4 a 3$ in the juvenile rat cerebellum is responsive to dietary $n-3$ PUFA, but additional studies are needed clarify the neurodevelopmental relationships between $n-3$ PUFA and Nr4a3 and the resulting impacts.
\end{abstract}

Keywords: juvenile; cerebellum; $n$-3 PUFA; next-generation sequencing; gene expression; brain development

\section{Introduction}

Childhood undernutrition is endemic throughout the world. Nutritional deficiency can severely impact neurodevelopment, and several lines of evidence indicate the importance of dietary long-chain polyunsaturated fatty acids (LCPUFA) in proper brain development. Within the brain, docosahexaenoic acid (DHA, 22:6n-3) and arachidonic acid (AA, 20:4n-6) are the most abundant LCPUFA. In humans, brain accumulation of LCPUFA begins prenatally and continues until the 2nd postnatal year as reviewed in Janssen \& Kiliaan 2014 [1]. During this period of infant neurodevelopment, LCPUFAs incorporate into cellular membranes, regulate gene expression, and facilitate neurogenesis [2,3]. 
Postnatal availability of LCPUFA is crucial for myelination of nerve fibers and neurite outgrowth [4-7]. Childhood deficiencies in LCPUFA are associated with cognitive, behavioral, and visual impairments in children and adolescents [1].

The rat cerebellum is primarily developed and remodeled postnatally; similarly, human cerebellar development carries into the first postnatal years [8-11]. In rat cerebellum, non-neuronal cells dynamically change their numbers by postnatal day 25 and approximately 150 million neurons are added within the first three postnatal months [9]. The cerebellum has long been recognized for regulating motor coordination but is also involved with higher cognitive function [12]. Early rat studies demonstrated that the developing cerebellum is particularly susceptible to undernutrition $[13,14]$.

DHA is obtained directly from the diet or is produced indirectly through its precursor $\alpha$-linolenic acid (ALA, 18:3n-3). Similarly, if AA is not obtained through dietary sources, it may be synthesized from its parent fatty acid linoleic acid (LA, 18:2n-6). Although less abundant than DHA or AA, brain docosapentaenoic acid (DPA $n-6,22: 5 n-6)$, resulting from the elongation and desaturation of AA, is linked to roles in brain health and function. Elevated content of DPA $n-6$ is considered a biomarker of $n-3$ PUFA deficiency in animal models [15]. The exact physiological role of DPA $n-6$ within the brain is not entirely clear, but increased levels of DPA $n-6$ are associated with deficits in learning and behavior [16].

Dietary LCPUFA content alters gene expression throughout the body in a tissue-specific manner [17]. LCPUFA directly bind and activate transcription factors that modulate expression of target genes [18]. For example, peroxisome proliferator-activated receptors (PPARs) are ligand-dependent transcription factors that bind specific $n-3$ and $n-6$ PUFAs and regulate gene expression [19]. Maternal n-3 PUFA deficient diets lead to elevated postnatal brain D2 (dopamine) receptors and D2 receptor mRNA levels in rats $[20,21]$. Genes important in the processes of synaptic plasticity and cognition are modified in the brains of rats fed PUFA-enriched diets with the expression of transthyretin (Ttr) being reduced and $\alpha$-synuclein (Snca) and calmodulins (Calm1-3) being increased [18,22].

Previous means of studying global LCPUFA-dependent differences in the transcriptome of the rodent brain have relied on RNA or cDNA microarray technology that analyzed a fraction of the genome [22-25]. Microarrays offer high-throughput expression analysis for thousands of genes between experimental conditions; although, the results are largely dependent on the selection/quality of probes used on the chip, along with other limitations [26]. Next-generation sequencing (NGS) or RNA-sequencing (RNA-seq) is a powerful alternative to microarray technology and is becoming more cost effective. NGS offers a global approach to measure differentially expressed genes (DEGs) that is not dependent on probes, and also displays greater sensitivity and dynamic range of quantification than microarrays $[26,27]$.

We have estimated that a three week old rat pup corresponds to an 11 month old child that has reached $70 \%$ maximum brain weight, and where myelination is still occurring within the corpus callosum and cerebellum by using an online model (http:/ / www.translatingtime.net/) to compare brain development across species [28]. In this study, we sought to identify the degree to which dietary $n-3$ PUFA deficiency modifies gene expression within the cerebellum of young rats given the neurodevelopmental importance of LCPUFA in postnatal brain health. We tested the hypothesis that a diet deficient in $n$-3 PUFA would result in modifications to the juvenile cerebellar transcriptome by characterizing the fatty acid profile and transcript abundance in the cerebellum of rats with variable levels of $n-3$ PUFA in their diets. A subset of transcripts that appeared to be differentially abundant between dietary classes from analysis of the RNAseq data, were validated with Quantitative PCR (qPCR) using RNA from two separate cohorts of animals. Cerebellar FA analysis demonstrated a 4-fold increase in DPA $n-6$, and slight increases of AA and docosatetraenoic acid (DTA; $22: 4 n-6$ ) in the cerebellum of CO-fed animals. Nr4a3 is an immediate early gene (IEG) that does not require de novo protein synthesis for its expression, therefore, can be activated and transcribed rapidly. Nr4a3 encodes a transcriptional activator that plays roles in neuroprotection and learning and memory formation. 
Nr4a3 was confirmed in both cohorts of animals to be elevated over 2-fold in the cerebellum from the $\mathrm{CO}$ diet.

\section{Materials and Methods}

\subsection{Reagents}

Hexane, 2-propanol, acetyl chloride, and butylated hydroxytoluene (BHT) were from Sigma-Aldrich, St. Louis, MO, USA. Nonadecanoic acid and fatty acid methyl ester standards were purchased from Nu-Chek Prep. Inc., Elysian, MN, USA.

\subsection{Animals}

All experiments were performed in accordance with the NIH guidelines for the use of live animals and were approved by the Institutional Animal Care and Use Committee of the USDA Agricultural Research Service, Grand Forks Human Nutrition Research Center. The animal experimentation and diets have been previously described and represent the same experimental conditions performed two separate times [29,30]. Male Sprague-Dawley rats (21 days old) were purchased from Envigo (Madison, WI, USA). Two days after arrival, rats were equally distributed, based on body mass, into two diet groups ( $n=10$ /group): diets containing soybean oil (SO) with replete $\alpha$-linolenic acid (ALA; 18:3n-3) with ad libitum (AL) intake and corn oil (CO) with AL intake. Oils constituted $16 \%$ fat energy. All diets were based on the AIN93G formula [31]. The SO diets had linoleic acid (LA; 18:2n-6) and ALA at $8.6 \%$ energy and $1.1 \%$ energy, respectively, whereas the CO diet had LA and ALA at $8.8 \%$ energy and $0.13 \%$ energy, respectively. The fatty acid composition of the oils were described previously with $\mathrm{SO}$ at $\sim 6.6 \mathrm{~mol} \%$ ALA and CO at $\sim 0.8 \mathrm{~mol} \%$ ALA [29].

Vitamin-free casein (Envigo) was used as a protein source. $\mathrm{CO}$ and $\mathrm{SO}$ were purchased from Dyets Inc (Bethlehem, PA, USA). All diets contained AIN93 mineral mix (Dyets Inc.) and AIN93G vitamin mix (Envigo). Caloric content of the diets was determined by bomb calorimetry as described previously [32]. Food consumption was measured daily, and fresh food was provided daily. Body mass was measured weekly. Body composition was determined by whole-body MRI (EchoMRI-700; Echo Medical Systems LLC, Houston, TX, USA) at the beginning and end of the study.

Rats remained in their dietary groups for four weeks. At the end of the experiment, rats were fasted overnight. Rats were killed by an overdose of anesthetic (xylazine $13 \mathrm{mg} / \mathrm{kg}$ and ketamine $100 \mathrm{mg} / \mathrm{kg}$ ) followed by exsanguination. The cerebellar region was dissected from the brain. Tissues were snap-frozen in liquid nitrogen and stored at $-80^{\circ} \mathrm{C}$. Tissues were pulverized using a BioPulverizer (Biospec Products, Inc., Bartlesville, OK, USA) at liquid nitrogen temperature. Pulverized samples were stored at $-80^{\circ} \mathrm{C}$ until further use.

\section{3. cDNA Library Preparation}

RNA was isolated from pulverized tissue ( 20 mg) using a QIAcube system (Qiagen, Valencia, CA, USA). RNA samples were treated with DNase I (New England Biolabs, Ipswich, MA, USA) for $10 \mathrm{~min}$ at $37^{\circ} \mathrm{C}$ followed by the addition of EDTA and a $10 \mathrm{~min}$ incubation at $70{ }^{\circ} \mathrm{C}$ to stop the reaction. RNeasy MinElute spin columns (Qiagen) were used to concentrate the RNA before rRNA depletion with RiboZero Gold human/mouse/rat (Illumina, San Diego, CA, USA) and a subsequent MinElute concentration. The RNA quality number (RQN) was assessed using a Fragment Analyzer automated capillary electrophoresis system (Advanced Analytical, Ankeny, IA, USA). Table A1 displays the RQNs for this study; the average RQN was 8.0. Library construction was completed with a ScriptSeq V2 Library Preparation Kit and ScriptSeq Index Primers (Epicentre, Madison, WI, USA) according to the protocol of the manufacturer. Final library profiles were validated using a Fragment Analyzer (Advanced Analytical Technology, Ames, IA, USA) and quantified by qPCR with NEBNext (New England Biolabs, Ipswich, MA, USA). The 20 libraries were combined in equimolar amounts to a pool and loaded at $1.8 \mathrm{pM}$ for sequencing with a 150 cycle high output paired end kit on a NextSeq 
500 platform (Illumina, San Diego, CA, USA) in a single run to preclude sequence run effects on the output. No libraries from other sources were included in the run. After the run, fastq files for libraries based on the index sequences were created using bcl2fastq v2.17 (Illumina, San Diego, CA, USA), with approximately $5 \%$ of reads unclassified.

\subsection{NGS Mapping and Data Normalization}

The sequencing data included 160 raw read files. Yield from the 20 cDNA libraries ranged from 11.0-54.9 million paired-end reads. Reads were adapter-trimmed using the BBDuk tool with options ktrim $=r k=23$ mink $=11$ hdist $=1 \mathrm{tpe}=\mathrm{t}$ tbo $=\mathrm{t}$. The rat genome (Rnor_6.0) was indexed in STAR [33] with a NCBI annotated splice junction file (GCF_000001895.5_Rnor_6.0_genomic.gff.gz) that was converted from gff to gtf format using the cufflinks gffread tool [34]. Trimmed reads were mapped to the rat genome with STAR options-outFilterIntronMotifs = RemoveNoncanonical— quantMode = TranscriptomeSAM, GeneCounts-outSAMtype = BAM SortedByCoordinate. The raw count matrix was created using column 3 of the GeneCounts output files following developer recommendations for stranded paired-end sequence data. NGS data are displayed in Table 3. Genes in the annotation file were identified as protein coding if they possessed a CDS annotation. Gene lengths were calculated in $\mathrm{R}$ by sorting exons by gene in GenomicFeatures summing lengths across all annotated exons for a gene while accounting for overlap between exons [35]. Upon manuscript acceptance, raw sequence data will be made publicly available through the NCBI sequence read archive (accession \# SRP144196). Trimmed data and assemblies are available from the authors upon request.

Counts were summarized by gene, resulting in 37,795 initial observations/rows. Prior to normalization, the summarized counts were filtered by removing rows with excessively missing, zero values, or low-value counts (2 or less) and then normalized using UQ scaling. After filtering, 17,109 genes remained for normalization (Table S1). Normalization of the sequencing data using Upper Quartile Scaling [36] was performed in JMP/Genomics 8.1 (SAS Institute, Inc., Cary, NC, USA), and normalized values were $\log 2$ transformed. For TPM normalization, the CDS only transcripts $(22,926)$ were subset from the initial observations. The CDS only observations were filtered as described above. After filtering, 14,487 observations remained for normalization (Table S2). Normalization of the CDS only sequencing data using TPM (transcripts per million) calculation [37] was performed in SAS 9.4 (SAS Institute, Inc., Cary, NC, USA), and normalized values were log2 transformed.

\section{5. qPCR Analysis}

RNA isolation and qPCR analysis have previously been described [38]. RNA was isolated from approximately $20 \mathrm{mg}$ of pulverized tissue by using the QIAcube system (Qiagen, Valencia, CA, USA) following the manufacturer's protocols. The quantity and quality of RNA were determined on a NanoDrop 8000 spectrophotometer (Thermo Fisher Scientific, Wilmington, DE, USA). RNA (1 $\mu \mathrm{g})$ was converted to cDNA using the high-capacity cDNA reverse transcription kit (Applied Biosystem, Inc., Carlsbad, CA, USA) following the manufacturer's protocols. Real time PCR reactions contained the following: 1X SYBR Green Master Mix (Applied Biosystem, Inc., Carlsbad, CA, USA), 300 nM of forward and reverse primers, and $40 \mathrm{ng}$ cDNA. Real Time PCR was performed on a Quantstudio 12k flex Real-Time PCR System (Applied Biosystem, Inc., Carlsbad, CA, USA). Real-time qPCR primers were designed and purchased from IDT (Coralville, IA, USA). Expression of candidate genes was normalized to $\beta$-actin expression levels and evaluated in comparison to the control (SO diet) using the $\Delta \triangle \mathrm{CT}$ method. Primer pairs for gene expression are presented in Table A2. 


\subsection{FA Analyses}

Lipids were extracted using hexane:isopropanol [39]. A powdered sample of tissue ( $\sim 50 \mathrm{mg})$ was extracted twice into $3.6 \mathrm{~mL}$ of hexane/2-propanol (3:2 v/v) with BHT (50 $\mu \mathrm{M}$; Sigma-Aldrich, St. Louis, MO, USA) added to limit lipid peroxidation. Samples were homogenized using a PRO200 Bio-Gen Series homogenizer (PRO Scientific Inc., Oxford, CT, USA) and then centrifuged at $2000 \times g$ for $10 \mathrm{~min}$. The organic phase was removed, dried under nitrogen, and dissolved in $1 \mathrm{~mL}$ of hexane/2-propanol $(3: 2 v / v)$ containing $5 \%$ water and $50 \mu \mathrm{M}$ BHT and stored at $-80{ }^{\circ} \mathrm{C}$ under nitrogen. The FA content of the organic extract was determined by fatty acid methyl ester (FAME) analysis using a Thermo Trace-1310 equipped with a TriPlus RSH Autosampler, (Thermo Fisher Scientific, Waltham, MA, USA) and a Supelco SP-2560 capillary column $(75 \mathrm{~m}, 0.18 \mathrm{~mm}$ ID, $0.14 \mu \mathrm{m}$ film thickness) as previously described [38]. Fatty acid methyl esters were prepared with the use of acetyl chloride [38].

\subsection{Statistical Analysis}

For NGS data, statistical analysis was performed on all normalized, log2-transformed data using ANOVA with differences between the two diet treatment groups as part of the ANOVA analysis for RNA-Seq in JMP Genomics (SAS Institute, Inc., Cary, NC, USA). The significance threshold was based upon the default Multiple Testing Method, Benjamini-Hochberg's FDR adjustment [40] and is set at 3.550 for the UQ scaling normalized data, and 3.430 for the TPM normalized data.

Statistical analysis of qPCR and FA data were done with GraphPad Prism version 7.00 for Windows (GraphPad Software, La Jolla, CA, USA, www.graphpad.com). Standard deviations of the mean were reported. Statistical significance was assessed with two-tailed Student's $t$-test with $p \leq 0.05$.

\section{Results}

\subsection{Energy Intake and Body Composition}

There were no differences in energy intake (data not shown), brain mass, or brain-to-body ratio between the rats consuming the $\mathrm{SO}$ or $\mathrm{CO}$ diets (Table 1). Within the 1st cohort, the liver and body mass of rats consuming the $\mathrm{CO}$ diets were slightly higher than rats consuming the $\mathrm{SO}$ diet but was unchanged in the 2nd cohort.

Table 1. Body composition in growing male rats.

\begin{tabular}{ccccccc}
\hline & \multicolumn{3}{c}{ 1st Cohort } & \multicolumn{3}{c}{ 2nd Cohort } \\
\hline Endpoint & SO & CO & $p$ & SO & CO & $p$ \\
\hline Body Mass (g) & & & & & & \\
Begin & $53.7 \pm 2.2$ & $54.8 \pm 2.7$ & 0.32 & $57.1 \pm 4.0$ & $57.4 \pm 4.1$ & 0.85 \\
End & $224.9 \pm 7.7$ & $235.9 \pm 10.2$ & 0.01 & $253.2 \pm 11.2$ & $253.8 \pm 15.5$ & 0.92 \\
Liver Mass (g) & $6.6 \pm 0.4$ & $7.3 \pm 0.7$ & $<0.01$ & $7.4 \pm 0.4$ & $7.3 \pm 0.5$ & 0.59 \\
Brain Mass (g) & $1.6 \pm 0.1$ & $1.6 \pm 0.1$ & 0.27 & $1.7 \pm 0.1$ & $1.7 \pm 0.1$ & 0.74 \\
Brain/Body (\%) & $0.69 \pm 0.04$ & $0.67 \pm 0.05$ & 0.43 & $0.65 \pm 0.03$ & $0.65 \pm 0.04$ & 0.93 \\
\hline
\end{tabular}

Data are reported as mean $\pm \mathrm{SD}, n=10$. Student's $t$-test was performed for each parameter. Bold indicates significance, $p<0.05$. CO: Corn oil; ER: Energy restriction; SO: Soybean oil.

\subsection{Cerebellar Fatty Acid Analysis}

Table 2 displays the cerebellar FA analysis of the rats used for generating the RNA-seq data. There were increases in AA, DTA, and n-6 DPA, but no decrease in DHA in the cerebellum of CO-fed animals. The 4-fold increase in $n$-6 DPA within the cerebellum of CO-fed rats was the most prominent FA modification between the groups. 
Table 2. Fatty acid concentration in the cerebellum of juvenile male rats.

\begin{tabular}{cccc}
\hline \multicolumn{4}{c}{ Tissue Concentration, $\boldsymbol{\mu m o l} / \mathbf{g}$} \\
\hline FAs & SO & CO & $p$ \\
\hline $16: 0$ & $17.23 \pm 2.16$ & $19.08 \pm 1.89$ & 0.06 \\
$18: 0$ & $14.62 \pm 1.92$ & $15.62 \pm 1.47$ & 0.21 \\
$20: 0$ & $0.35 \pm 0.06$ & $0.33 \pm 0.04$ & 0.53 \\
$22: 0$ & $0.22 \pm 0.03$ & $0.22 \pm 0.03$ & 0.94 \\
$24: 0$ & $0.22 \pm 0.05$ & $0.23 \pm 0.04$ & 0.97 \\
$16: 1 n-7$ & $0.30 \pm 0.03$ & $0.30 \pm 0.03$ & 0.74 \\
$18: 1 n-7$ & $3.37 \pm 0.44$ & $3.60 \pm 0.35$ & 0.22 \\
$18: 1 n-9$ & $14.19 \pm 2.03$ & $14.76 \pm 1.35$ & 0.47 \\
$20: 1 n-9$ & $1.50 \pm 0.24$ & $1.42 \pm 0.16$ & 0.42 \\
$22: 1 n-9$ & $0.18 \pm 0.02$ & $0.17 \pm 0.03$ & 0.37 \\
$18: 2 n-6$ & $1.29 \pm 0.19$ & $1.23 \pm 0.13$ & 0.44 \\
$20: 2 n-6$ & $0.35 \pm 0.06$ & $0.33 \pm 0.03$ & 0.51 \\
$20: 3 n-6$ & $0.41 \pm 0.07$ & $0.40 \pm 0.03$ & 0.42 \\
20:4n-6 (AA) & $6.11 \pm 0.81$ & $6.96 \pm 0.61$ & $\mathbf{0 . 0 2}$ \\
22:4n-6 (DTA) & $1.92 \pm 0.28$ & $2.33 \pm 0.19$ & $<\mathbf{0 . 0 1}$ \\
22:5n-6 (DPAn6) & $0.27 \pm 0.03$ & $1.13 \pm 0.17$ & $<\mathbf{0 . 0 1}$ \\
$n-6$ LCPUFAs ${ }^{1}$ & $9.06 \pm 1.22$ & $11.15 \pm 0.93$ & $<\mathbf{0 . 0 1}$ \\
$22: 5 n-3$ & $0.31 \pm 0.12$ & $0.27 \pm 0.11$ & 0.42 \\
22:6n-3 (DHA) & $10.13 \pm 1.33$ & $10.01 \pm 0.85$ & 0.81 \\
$n-3$ LCPUFAs ${ }^{2}$ & $10.44 \pm 1.39$ & $10.27 \pm 0.85$ & 0.75 \\
\hline
\end{tabular}

Data are reported as mean $\pm \mathrm{SD}, n=10$. Student's $t$-test was performed for each parameter. Bold indicates significance, $p<0.05 .{ }^{1} n-6$ LCPUFAs sums all $n$-6 PUFAs except 18:2n-6. ${ }^{2} n-3$ LCPUFAs sums all $n$-3 PUFAs. CO: corn oil; FA: Fatty acid; LCPUFA: Long-chain polyunsaturated fatty acid; SO: Soybean oil.

\subsection{Next-generation Sequencing of Rat Cerebellum}

Table 3 outlines the sequencing data. There was a five-fold span in range for the raw paired reads $(11,037,221$ to $54,876,507)$ and the reads that uniquely mapped to the rat genome $(8,945,862$ to $45,878,644)$ but were not significantly different ( $p=0.3226$ and $p=0.2454$, respectively) between the two diet treatments. Approximately, $80 \%$ of the reads mapped uniquely to the rat genome. On average this correlated to just over 21,000 annotated genes identified with a range of 19,354 to 23,180 .

Table 3. Next-generation sequencing data.

\begin{tabular}{cccccc}
\hline Group & ID & Paired Reads & Uniquely Mapping & $\%$ & Annotated Transcripts \\
\hline \multirow{6}{*}{ SO } & 23552 & $16,672,271$ & $12,849,214$ & 77.1 & 20,399 \\
& 23553 & $22,682,731$ & $19,036,095$ & 83.9 & 20,944 \\
& 23554 & $14,456,057$ & $11,930,561$ & 82.5 & 19,577 \\
& 23555 & $29,567,630$ & $19,869,689$ & 67.2 & 21,578 \\
& 23556 & $28,959,204$ & $23,777,578$ & 82.1 & 21,562 \\
& 23557 & $17,119,385$ & $13,192,970$ & 77.1 & 20,715 \\
& 23558 & $11,037,221$ & $8,945,862$ & 81.1 & 19,354 \\
& 23559 & $36,432,242$ & $30,316,383$ & 83.2 & 22,242 \\
& 23560 & $33,211,308$ & $27,063,716$ & 81.5 & 21,985 \\
CO & 23561 & $49,759,399$ & $36,660,886$ & 73.7 & 22,787 \\
& 23562 & $15,976,576$ & $13,229,505$ & 82.8 & 20,080 \\
& 23563 & $24,312,065$ & $18,465,257$ & 76.0 & 21,272 \\
& 23564 & $16,002,390$ & $13,155,503$ & 82.2 & 20,556 \\
& 23565 & $48,831,450$ & $38,802,478$ & 79.5 & 23,180 \\
& 23566 & $23,814,884$ & $19,463,164$ & 81.7 & 21,361 \\
& 23568 & $17,616,302$ & $14,507,861$ & 82.4 & 20,296 \\
& 23569 & $54,876,507$ & $44,754,936$ & 81.6 & 22,953 \\
& 23570 & $54,528,411$ & $45,878,644$ & 84.1 & 22,850 \\
& 23571 & $31,881,735$ & $26,108,279$ & 81.9 & 21,694 \\
& 23567 & $35,021,051$ & $28,774,451$ & 82.2 & 21,789 \\
\hline
\end{tabular}

$\%$ is the percentage of paired reads that uniquely mapped to the rat genome (Rnor_6.0). CO: Corn oil; ID: sample identification number; SO: Soybean oil. 


\subsection{Upper Quartile (UQ) Scaling Normalization}

Figure 1 is a representative two-way clustering heat map generated from data normalized by UQ scaling. The heat map shows that a majority of the samples clustered together according to their respective diet treatment (SO or CO). However, four SO samples (23,556, 23,559, 23,560, and 23,561) did not cluster as tightly with the other samples within the SO diet group, indicating that there may be noise in the data which is unaccounted for compared to the main effect. The data was analyzed for DEGs between the diet treatments using analysis of variance (ANOVA). Figure 2 is a volcano plot for the diet comparisons of DEGs within the samples. 100 genes were identified to be differentially expressed between the two diet groups. Altogether, 90 genes increased while 10 decreased from the $\mathrm{CO}$ diet with fold-changes ranging from 3.73-0.62 (Table S3).

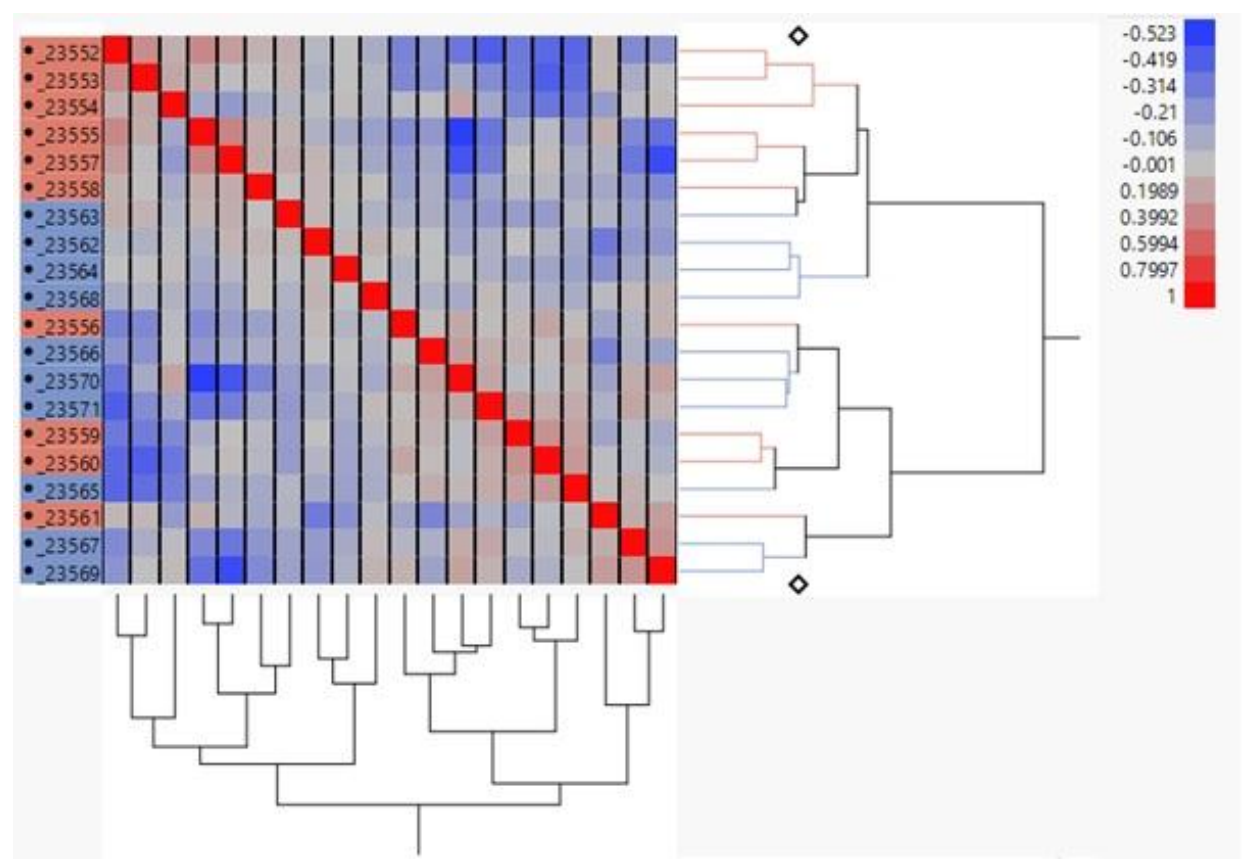

Figure 1. Correlation heat map of NGS-identified transcripts using upper quartile scaling normalization. The heat map represents the graphical display resulting from unsupervised clustering of the correlations between samples. The $x$ - and $y$-axis are the same and the red diagonal line represents a correlation of 1 . The pink labeled IDs are associated with the soybean diet while the blue labeled IDs are from the corn oil diet.

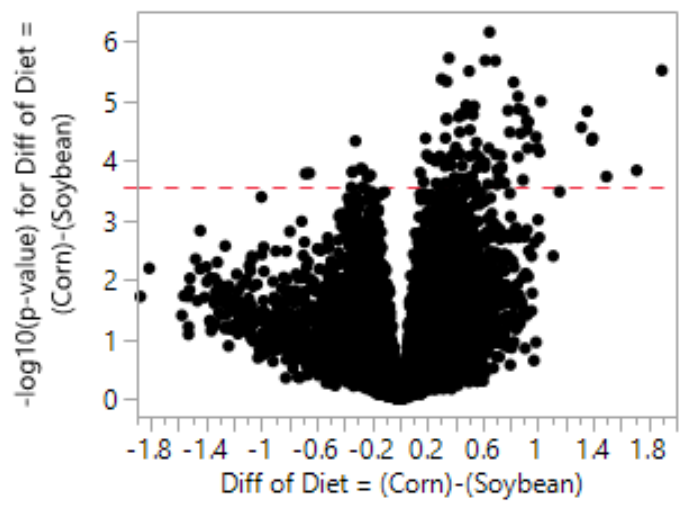

Figure 2. Volcano plot of NGS-identified transcripts using upper quartile scaling normalization. The $x$-axis displays the difference in $\log$ scale, and the $y$-axis plots the-log $10(p$-value) for each transcript, represented by a point. Significance threshold is graphed with a dotted red line (3.550). Points to the right of 0 and above the significance threshold are significantly increased transcripts and transcripts that are significantly decreased are to the left of 0 and above the threshold line. 


\subsection{Transcripts per Million (TPM) Normalization}

Figure A1 in Appendix B is the corresponding two-way clustering heat map generated from data normalized by TPM. The TPM heat map is similar in clustering to the UQ scaling heat map. As described above for UQ scaling, we analyzed the data for DEGs between the diet treatments. Figure A2 is a representative volcano plot for the TPM diet comparisons of DEGs within the samples. 107 genes were identified to be differentially expressed between the two diet groups. Altogether, 81 genes increased while 26 genes decreased from the $\mathrm{CO}$ diet with fold-changes ranging from 3.83-0.52 (Table S3).

\subsection{Comparison of UQ Scaling and TPM Normalization}

When comparing the separate normalizations, approximately $70 \%$ of the genes overlapped that were identified as differentially expressed between the two groups (Figure 3 and Table 4). All the genes displaying at least two-fold differences were identified using both normalization methods, with the exception of Rnr1 and Rnr2 that were identified with UQ scaling exclusively. Rnr1 and Rnr2 are non-coding mitochondrial ribosomal RNAs (mt-rRNA, 12S and 16S subunits) and were filtered out during TPM normalization. Also, noteworthy was the fact that roughly $90 \%$ of DEGs identified displayed differences less than two-fold (Table S3).

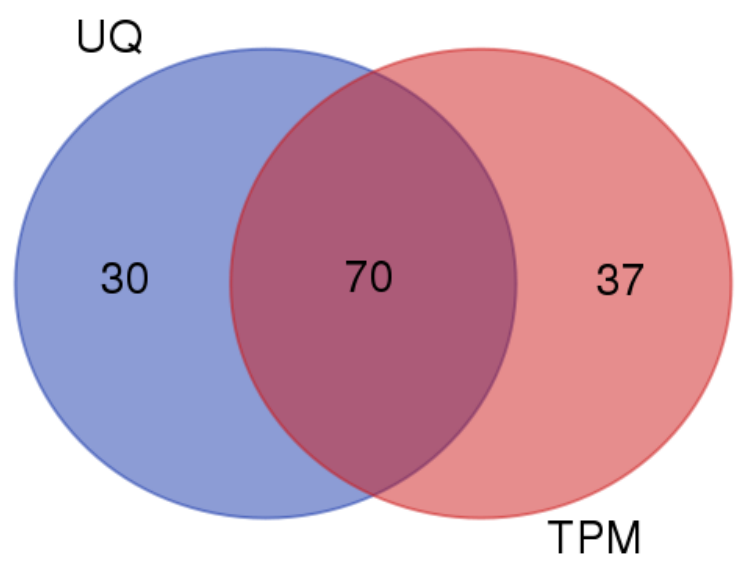

Figure 3. Venn diagram comparison of differentially expressed genes identified with NGS using separate data normalizations. The light pink circle represents the number of genes that were exclusively identified using TPM normalization, while the blue circle represents the number of genes that were exclusively identified using UQ scaling normalization. The dark pink oval represents the genes that overlapped between the TPM and UQ scaling normalizations.

Table 4. Differentially Expressed Genes Identified Specific to Data Normalization.

\begin{tabular}{cll}
\hline Normalization & Total & \multicolumn{1}{c}{ Genes } \\
\hline & & Ube2l3, Atp6v1h, Dusp1, Trnp1, Dbndd2, Scpep1, Tmem42, Thy1, Tlk1, Phactr3, Ndufa9, Gmfb, \\
& Klhl11, C2cd3, Opalin, Tmem231, Ptafr, Gstt3, Nrn1, Elovl2, Atp5g3, Tmem206, March8, S100b, \\
& Fam13c, Tbc1d15, Hsp90ab1, Ftsj1, Asrgl1, Htra1, Gga3, Pitrm1, Rnasek, Rpl7l1, Tgfa, Ifngr1, \\
& Sox8, Scamp3, Pgap2, Tspan1, Elp5, Ldoc1, Anp32b, Yars, Cpe, Klhl2, Fam220a, Mpzl1, Zfp212, \\
& LOC314140, Mrpl40, Sh2b2, Nxph4, Idh3a, Sec62, Ankrd40, Stmn2, Nr4a3, Bfar, Atp6v0c, \\
& Rps16, Hsbp1, LOC100911248, Ndufa3, Lix1l, Zfp449, Ralbp1, Dnajc7, Srfbp1, Smim17 \\
& LOC108351039, LOC103692551, Pik3cb, Ttc33, Socs5, LOC103690204, Prepl, Rnr1, Rcbtb2, \\
& Ppp3r1, Wee1, Noa1, Mfsd11, Gatm, Gmcl1, Rnr2, Pde4b, Tmem214, Meis3, Errfi1, Trnm, \\
& Mbtd1, Cnih1, Rab7a, Vac14, Trap1, Clcn4, Amz2, Ywhae, Aida \\
\hline \multirow{3}{*}{30} & Nlrp3, Golga5, Ube2j2, Ica1, Snrpa1, Gtf2f2, Abcf2, Uvrag, Vps45, Stim2, Metap2, Kpna1, \\
& Nkain4, Nutf2, Rundc1, Ppp1r8, Tnpo3, Pithd1, Osbpl2, Samd10, Fbxw4, Cul1, Ptpmt1, \\
& Tmem184c, Cdc34, Cnrip1, Atp5a1, Metap1, Ppcs, Vdac2, Pold3, Cetn2, Mrpl9, Ndufb7, Qrich2, \\
& Pex3, Gadd45gip1 \\
\hline \multirow{3}{*}{37} & UQ: UPM
\end{tabular}

UQ: Upper quartile; TPM: Transcripts per million. 


\subsection{Quantitative Real-Time PCR}

We then chose to validate several (39 genes) of the NGS identified DEGs with qPCR (Table S3). We validated genes based upon the level that they were differentially expressed (i.e., top 10 genes elevated or reduced in the UQ or TPM lists) but also chose several genes based upon their involvement with energy production (Atp5g3, Atp6v1h), electron transport (Ndufa9, Ndufa3), cell proliferation or apoptosis (Tgfa, Anp32b), cell signaling or cell cycle (Dusp1, Sh2b2), neurotransmission or neurodevelopment (Nrn1, Asrgl1), and myelination (Opalin, Mpzl1). We validated NGS data with qPCR not only in the animals used for RNA-seq analysis but also in animals from a separate but identically repeated study using the same dietary treatments. The validation of gene expression in the 2 nd cohort of animals provided biological replication of the data, and is not just a validation of the RNA-seq results.

Table S3 displays the qPCR validations for UQ scaling and TPM normalizations. Two genes (Nr4a3 and Smim17) that overlapped between the normalizations, three genes (Tmem214, Phactr3, and $A m z 2$ ) exclusively identified by UQ scaling, and one gene (Gtf2f2) exclusively identified by TPM were validated by qPCR in the 1st cohort of animals. However, only Nr4a3, whose gene product is a nuclear orphan receptor involved in transcription regulation, was confirmed in the 2nd cohort of animals to be elevated over 2-fold in the cerebellum of rats consuming the CO diet (Table S3 and Figure 4). Interestingly, eight genes (Cpe, Scamp3, Tgfa, Sh2b2, Opalin, Ndufa9, Ndufa3, and Atp6v1h) identified as being higher in CO rats by both UQ scaling and TPM normalizations were confirmed to go the opposite direction via qPCR in the 1st cohort of animals, displaying lower levels in the CO compared to SO animals (Table S3). Cerebellar Tgfa, whose gene product is a ligand for the epidermal growth factor receptor (EGFR), was further validated in the 2nd cohort of animals to be reduced in rats consuming $\mathrm{CO}$ diet.

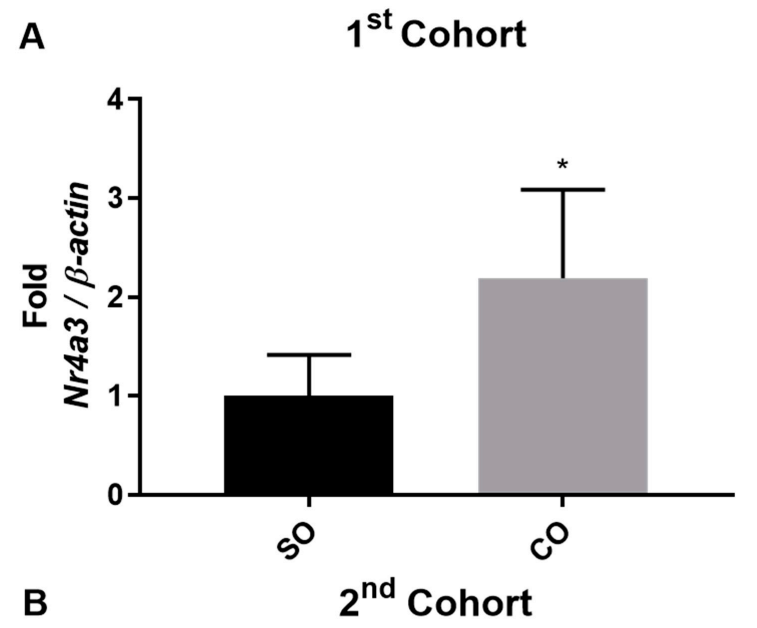

B

$2^{\text {nd }}$ Cohort

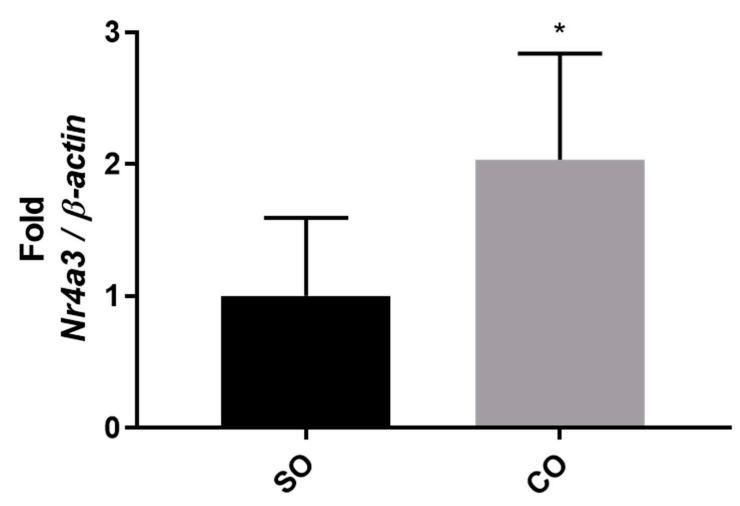

Figure 4. Cerebellar qPCR measurement of Nr4a3. Data are reported as mean $\pm \mathrm{SD}, n=10$ * Statistical significance was assessed using Student's $t$-test performed on the initial $\Delta \mathrm{Ct}$ values for the gene with $p \leq 0.05$. CO: Corn oil; SO: Soybean oil; $\Delta \mathrm{Ct}$ : Change in cycle threshold normalized to $\beta$-actin. 


\section{Discussion}

Undernutrition during early brain development can result in serious deficits in cognition, behavior, and motor skills that may have lasting consequences [41]. LCPUFA deficiency during brain development displays similar impairments [1]. Still, data is limited in describing what genes are altered within the transcriptome of the juvenile cerebellum in response to dietary $n-3$ PUFA deprivation.

In this study we identified 137 potential dietary $n$-3 PUFA-responsive genes within the cerebellar transcriptome of developing rats using NGS. In comparison, data obtained from the earlier cDNA microarray studies identified 102 DEGs [22], 23 DEGs [25], 24 DEGs [24], and 6 DEGs [23] in rat brains by modifying dietary $n-3$ and $n-6$ PUFA content. This correlates to roughly $0.50-0.70 \%$ (dependent on normalization) DEGs identified with NGS and the earlier studies ranged $0.20-3.40 \%$ (dependent on study). By using qPCR, we were only able to confirm that 6 of the 39 genes changed in the same direction (qualitatively consistent) with NGS data, correlating to roughly a 15\% validation rate in the 1st cohort of animals. Of the 6 genes we were able to confirm in the 1st cohort, only 1 gene (Nr4a3) could be confirmed in the repeated study (2nd cohort). To our knowledge, brain expression of $N r 4 a 3$ has not previously been reported to be responsive to dietary $n-3$ or $n-6$ PUFA content and was not identified as a DEG in the microarray studies listed above. It is important to note, however, that the earlier studies used different rat strains, age of rats, duration on diets, oil composition and content of $n-3$ and $n-6$ PUFA within diets, whole brain or hippocampal tissue, and RNA samples were pooled 8-12 animals/group. So, a fair comparison between the earlier studies and the current study cannot be made.

The majority of the cerebellar DEG fold-changes in this study were $<2$-fold. This finding is consistent with a previous RNA microarray study examining DEGs within the cerebral cortex of young baboons that were fed diets that differed in amounts of DHA and AA for 12 weeks [42]. Furthermore, a more recent microarray study that analyzed modifications in the mouse brain transcriptome by altering dietary $n-3$ to $n-6$ levels for 20 weeks, identified roughly 1000 genes of interest but less than $8 \%$ were $>2$-fold changes [43]. These microarray studies identified more potential $n-3$ and $n-6$ PUFA responsive genes within the brain; however, the extent to which the DEGs were modified was low. While there are several important experimental design differences compared to our study, namely dietary $n-3$ and $n-6$ LCPUFA content and duration on diets, the LCPUFA-dependent modifications within the brain transcriptome was relatively small, which is consistent with our results. These results are quite different from a recent study analyzing effects of dietary $n-3$ and $n-6$ PUFA within the pig liver transcriptome that report over 3500 DEGs with average fold-changes of 9.4 [44]. These previous data, in addition to our data, indicate that the brain transcriptome is tightly regulated with regard to dietary $n-3$ PUFA.

The most prominent finding in this study was identifying and confirming the elevated expression of Nr4a3 from CO in both cohorts of animals. Nr4a3 (gene product-NOR1) is a transcriptional activator known for playing important roles in cell survival and apoptosis $[45,46]$. The Nr4a gene family regulates the neuroendocrine system which is responsible for energy utilization and metabolism [47]. In the brain, $\mathrm{Nr} 4 a 3$ is capable of providing neuroprotection and promoting neuronal survival upon excitotoxic and oxidative stress generated from kainic acid, a glutamate analog, in the hippocampus of mice $[48,49]$. Moreover, Nr4a3 and other related Nr4a gene members are elevated after learning and memory formation in mice and their activation is associated with increased synaptic plasticity $[50,51]$. Previous studies using mouse skeletal muscle cells and tissue have shown that Nr4a3 plays a role in regulating genes involved with fatty acid utilization and is inducible by the beta-adrenergic receptor agonist isoprenaline [52,53]. In beta cells of the pancreas, Nr4a3 is inducible by FAs (palmitate) and can modulate secretion of insulin and expression of the Ins1 and Ins2 genes [54]. From our results, it is not clear if the modified level of $N r 4 a 3$ within the cerebellum is an adaptive response to the stress imposed by dietary $n-3$ PUFA deprivation, or if dietary $n-3$ PUFA deprivation is causing cognitive disturbances. More work is needed to answer these questions.

Reductions in DHA are observed in the rat brain from trans-generational dietary n-3 PUFA deprivation $[55,56]$. Under natural conditions (non-trans-generationally deprived of dietary $n-3$ PUFA), the postnatal rat brain is effective in accumulating DHA required for growth and is effective in limiting 
DHA loss during times of dietary $n-3$ deprivation [57]. The juvenile $n-3$ PUFA deficient rat model used in this study is efficient in depleting $n-3$ PUFA from livers and altering the brain FA content $[29,30]$. In prior studies, we have observed small $(\sim 10 \%)$ reductions in cerebellar levels of DHA and increases in DPA $n-6, A A$, and DTA using the CO diet in postnatal rats $[29,30]$. The cerebellar FA content reported here is in good agreement with our earlier studies, with the exception of the DHA reduction in the brains of young rats fed $\mathrm{CO}(\sim 0.8 \mathrm{~mol} \%$ ALA $)$ for four weeks. This finding is not unexpected, since the DHA reduction demonstrated previously was minor and $\sim 15$ weeks is needed to have more prominent reductions in brain DHA when rats are fed diets utilizing this percentage of ALA [58].

A longer postnatal duration of dietary n-3 PUFA deprivation or initiating deprivation prenatally may have resulted in a more pronounced effect to the LCPUFA content within the cerebellum and reduced DHA more effectively. More prominent alterations to the cerebellar LCPUFA composition could have resulted in greater fold changes to the DEGs identified in this study or generated an entirely different list of DEGs. Additional studies are needed to assess the possible health consequences associated with the cerebellar LCPUFA-dependent modification of Nr4a3 expression during development and whether these effects are reversible.

This study has limitations. The cellular heterogeneity of the postnatal cerebellum coupled to its dynamic growth and remodeling during this period of time add complexity in measuring DEGs within this important developing tissue. A majority of the DEGS identified displayed only minor changes ( $<2$-fold) and from a statistical standpoint, there is an abundance of NGS data ( $n=10 /$ group). This results in increased precision around the estimated means and potentially Type II statistical errors. However, we performed qPCR validations on a 2nd cohort of animals to provide biological replication and reduce the impacts of statistical anomalies.

\section{Conclusions}

This study provides insight about the transcriptomic modifications within the juvenile rat cerebellum imposed by changing $n-3$ PUFA content of the diet. Several potential $n-3$ PUFA responsive genes were identified, however, only Nr4a3 was confirmed to be elevated over 2-fold from the CO diet. In the brain, $\mathrm{Nr} 4 \mathrm{a} 3$ provides neuroprotection but is also involved in cognition and memory formation. This work provides a foundation for developing future studies to better understand what mechanisms are involved with LCPUFA regulation of brain $\mathrm{Nr} 4 a 3$ expression. Additional research is needed to clarify whether synaptic plasticity, learning, or memory formation is affected in these developing animals given the neurodevelopmental importance of LCPUFA along with the important functions of $N r 4 a 3$ within the brain.

Supplementary Materials: The following are available online at http:/ / www.mdpi.com/2072-6643/11/2/407/s1, Table S1: Genes quantified using upper quartile scaling, Table S2: Genes quantified using transcripts per million, Table S3: NGS DEGs with qPCR validation in two separate animal cohorts.

Author Contributions: A.A.M., M.J.P., and T.P.L.S. contributed to the conception and design of the study. T.P.L.S. was responsible for generation of RNA-seq data. A.A.M. and M.J.P. interpreted data and wrote the manuscript. A.M.D. performed bioinformatics analyses, K.M.Y. performed statistical analyses, and they contributed to data interpretation and manuscript preparation. All authors contributed to review and revision of the manuscript and agreed to be accountable for the content of the work.

Funding: This project was supported by the USDA Agricultural Research Service projects 3062-51000-053-00D and 3040-31000-100-00D. The USDA Agricultural Research Service, Plains Area, is an equal opportunity/affirmative action employer, and all agency services are available without discrimination. Mention of trade names or commercial products in this article is solely for providing specific information and does not imply recommendation or endorsement by the USDA.

Acknowledgments: The authors would like to thank William Thompson, Jacky Carnahan, Brian Gregoire, and Joseph Idso for their technical assistance.

Conflicts of Interest: The authors declare no conflict of interest. 


\section{Appendix A}

Table A1. RNA quality used in analysis.

\begin{tabular}{ccc}
\hline Group & Sample & RQN \\
\hline \multirow{6}{*}{ SO } & 23,552 & 8.1 \\
& 23,553 & 8.2 \\
& 23,554 & 7.0 \\
& 23,555 & 8.2 \\
& 23,556 & $*$ \\
& 23,557 & 8.1 \\
& 23,558 & 8.2 \\
& 23,559 & 8.2 \\
& 23,560 & 8.4 \\
& 23,561 & 8.3 \\
\hline \multirow{6}{*}{ CO } & 23,562 & 8.1 \\
& 23,563 & 7.7 \\
& 23,564 & 8.1 \\
& 23,565 & 8.3 \\
& 23,566 & 7.9 \\
& 23,568 & 8.2 \\
& 23,569 & 7.9 \\
& 23,570 & 6.6 \\
& 23,571 & 8.2 \\
& 23,567 & 8.6
\end{tabular}

* Instrument error. CO: Corn oil; RQN: RNA quality number; SO: Soybean oil.

Table A2. qPCR primer sequences.

\begin{tabular}{|c|c|c|}
\hline Gene & Forward & Reverse \\
\hline Meis3 & GCTCСТCTGACTCСТTCAATG & ATCCTCGATCACCAGGTCTAT \\
\hline Tmem 214 & GCTGCAAGAGCTGGATAAGA & CTTTGGTGAGGTTGGGATACA \\
\hline Ralbp1 & ACCAAGATTGCACAGGAGATAG & CTGGGCAAGGAGGATATTTATGA \\
\hline Tmem42 & CCCTGATGTGGACCTTCTTTAG & CTAAGATGGCCGAGCAAAGTA \\
\hline Noa1 & CGGGCTATGGAGTTGAAGAA & AGGAGTCGGGTTGCAAATAG \\
\hline Phactr3 & CCGTGGAAGAACTGGAAAGA & CTTGTCTGCTCTCCTGTCATAG \\
\hline Trap1 & GCTGACCAGCTTATCAGACTAC & CTCCACAGAGATCAGCTTCTTC \\
\hline$A m z 2$ & CTGCGACTAAGTGCTCCTTTA & CTTCACGCTGCCTTCATATTTC \\
\hline Smim17 & CAGCTGTGACAGTGATGAGAA & TGGAGCATCATGGGCATC \\
\hline Scamp3 & CAGGCACTCGACAGAACAA & GACAAAGGAGCAGGGAGTAAA \\
\hline Cpe & GAGTGGTACTGCTCACGAATAC & GGTCACGGACAAACCCTTTA \\
\hline Atp6v0c & СTTATCGCTAACTCCCTGACTG & AAGCACCTCCGCAAAGAT \\
\hline Gstt3 & CAGCATTACACTGATGCCTTTG & GTCAGGTGCCTTGTACTTTCT \\
\hline Nxph4 & CACCAAGAGAAAGCCATCCA & CAGCGAGAACTTGAGGGTATG \\
\hline Ldoc1 & TGCGAATACTGGTGTGTGAG & ACAGGAGGCTGATCAAGAATG \\
\hline Nr4a3 & GCAGAGCCTGAACCTTGATA & CATAGCTCСTCCACTCTCTTTG \\
\hline LOC100911248 & TGTCTCAGCACCCAACTTATC & CAACGTAAGGGACAGGAATCA \\
\hline Rps16 & CAAGTTACTGGAGCCTGTTCTG & CCGATCGTACTGGATGAGGATA \\
\hline Qrich2 & GGCCTTGATGGACACATCTATAA & CTGGAGCTTAGCCTTGTTGT \\
\hline$V p s 45$ & CCCTGGACCATCTCATCAAAG & CATAGGTGGCTCCTCCAATAAC \\
\hline Cdc34 & GACCTCTTCTACGACGACTACTA & GCCAGAGTCATCCTCTTCATC \\
\hline mrpl9 & GTACTGGTGTGATGTGACAGTAA & GGCTAACCAGTGCTTGTATCT \\
\hline Gadd45gip1 & GCCCGATTCCAGGAACTATTAC & GCAATTCGAGCCTCCTTCTT \\
\hline Fbxw4 & TGCTTACACACCATCCAGAC & TGAGAAGTGCCCACAACAA \\
\hline$G t f 2 f 2$ & CCTGTGGGATACCTGAAAGAAA & CCTCTGTTTGGTAATGCCTGTA \\
\hline Pithd1 & GGGCAATGTCAAGCTCAAAG & GTCTGGCTCCCTTTCTGTATC \\
\hline Ppcs & CAGACCCGGACATCATCATTAG & GTCCTCAGACAGCAGTAACTTT \\
\hline $\operatorname{Sh} 2 b 2$ & GTGGTGTCAGTGAGAGCAATAA & GCCGTGACCATTCAGAGAAA \\
\hline Tgfa & CCAGATTCCCACACTCAGTATT & GGATCAGCACACAGGTGATAA \\
\hline Anp32b & GTCACTAACCGGAGTGATTACC & САТСТТСТТССТССТСАССАТС \\
\hline Dusp1 & CTAACCACTTTGAGGGTCACTAC & GATAATACTCCGCCTCTGCTTC \\
\hline Nrn1 & GGGCGAAAGATATGTGGGATAA & CTGCCGCAGAGTTCGAATAA \\
\hline Asrgl1 & CAAGAAGCACCTGGAGAAAGA & GGCCAGATTCACCTTCAGAATA \\
\hline Opalin & GCTGGTAGCCTTGCTGTTTA & CСАССAAAGACСТСТTСТTСТС \\
\hline Ndufag & TCCGCTTTCAGGTTGTTAGAG & GCATCCCACTCCAGAAAGATAA \\
\hline Ndufa3 & AAAGAACCACAACTCCCAGAG & ACAGGTTCTTGAGCCATTCC \\
\hline Atp5g3 & GGAGAGGGCTCTACGGTATTTA & GAGACCCATAGCTTCAGACAAG \\
\hline Mpzl1 & GGCTCCATGTGGTGGAAATA & GTGGTCTAACTGTGCGTATATGA \\
\hline Atp6v1h & CCAAGAGTATGCTCTGGCTATG & CCACCGAGCTGCTCAATAA \\
\hline$\beta$-actin & GTGTGGATTGGTGGCTCTATC & CAGTCCGCCTAGAAGCATTT \\
\hline
\end{tabular}




\section{Appendix B}

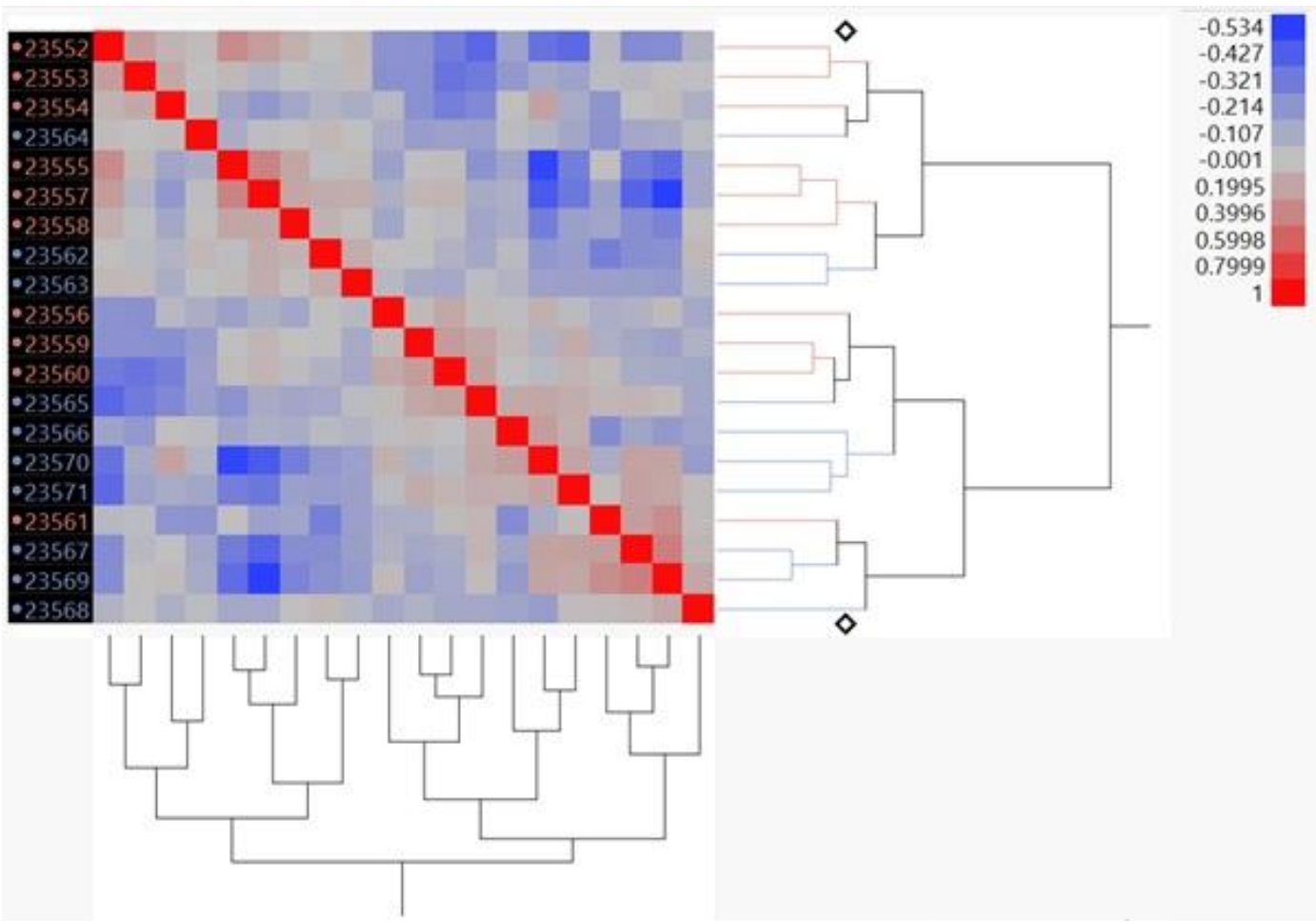

Figure A1. Correlation heat map using transcripts per kilobase million normalization. The heat map represents the graphical display resulting from unsupervised clustering of the correlations between samples. The $x$ - and $y$-axis are the same and the red diagonal line represents a correlation of 1 . The pink labeled IDs are associated with the soybean diet while the blue labeled IDs are from the corn oil diet.

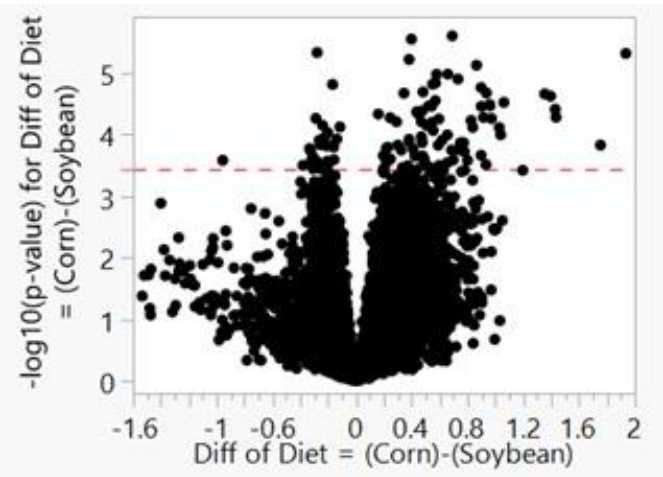

Figure A2. Volcano plot for upper transcripts per kilobase million normalization. The $x$-axis displays the difference in log scale, and the $y$-axis plots the $-\log 10$ ( $p$-value) for each transcript, represented by a point. Significance threshold is graphed with a dotted red line (3.430). Points to the right of 0 and above the significance threshold are significantly increased transcripts, and transcripts that are significantly decreased are to the left of 0 and above the threshold line. 


\section{References}

1. Janssen, C.I.F.; Kiliaan, A.J. Long-chain polyunsaturated fatty acids (LCPUFA) from genesis to senescence: The influence of LCPUFA on neural development, aging, and neurodegeneration. Prog. Lipid Res. 2014, 53, 1-17. [CrossRef] [PubMed]

2. Maekawa, M.; Takashima, N.; Matsumata, M.; Ikegami, S.; Kontani, M.; Hara, Y.; Kawashima, H.; Owada, Y.; Kiso, Y.; Yoshikawa, T.; et al. Arachidonic Acid Drives Postnatal Neurogenesis and Elicits a Beneficial Effect on Prepulse Inhibition, a Biological Trait of Psychiatric Illnesses. PLoS ONE 2009, 4, e5085. [CrossRef] [PubMed]

3. Belkind-Gerson, J.; Carreon-Rodriguez, A.; Contreras-Ochoa, C.O.; Estrada-Mondaca, S.; Parra-Cabrera, M.S. Fatty acids and neurodevelopment. J. Pediatr. Gastroenterol. Nutr. 2008, 47, S7-S9. [CrossRef]

4. Calderon, F.; Kim, H.Y. Docosahexaenoic acid promotes neurite growth in hippocampal neurons. J. Neurochem. 2004, 90, 979-988. [CrossRef] [PubMed]

5. Cao, D.; Xue, R.; Xu, J.; Liu, Z. Effects of docosahexaenoic acid on the survival and neurite outgrowth of rat cortical neurons in primary cultures. J. Nutr. Biochem. 2005, 16, 538-546. [CrossRef]

6. Bourre, J.M.; Pascal, G.; Durand, G.; Masson, M.; Dumont, O.; Piciotti, M. Alterations in the fatty acid composition of rat brain cells (neurons, astrocytes, and oligodendrocytes) and of subcellular fractions (myelin and synaptosomes) induced by a diet devoid of $n-3$ fatty acids. J. Neurochem. 1984, 43, 342-348. [CrossRef] [PubMed]

7. Liu, J.W.; Almaguel, F.G.; Bu, L.; De Leon, D.D.; De Leon, M. Expression of E-FABP in PC12 cells increases neurite extension during differentiation: Involvement of $n-3$ and n-6 fatty acids. J. Neurochem. 2008, 106, 2015-2029. [CrossRef] [PubMed]

8. Altman, J. Autoradiographic and histological studies of postnatal neurogenesis. 3. Dating the time of production and onset of differentiation of cerebellar microneurons in rats. J. Comp. Neurol. 1969, 136, 269-293. [CrossRef] [PubMed]

9. Bandeira, F.; Lent, R.; Herculano-Houzel, S. Changing numbers of neuronal and non-neuronal cells underlie postnatal brain growth in the rat. Proc. Natl. Acad. Sci. USA 2009, 106, 14108-14113. [CrossRef] [PubMed]

10. Ten Donkelaar, H.J.; Lammens, M.; Wesseling, P.; Thijssen, H.O.; Renier, W.O. Development and developmentaldisorders of the human cerebellum. J. Neurol. 2003, 250, 1025-1036. [CrossRef] [PubMed]

11. Benjamini, Y.; Hochberg, Y. Controlling the False Discovery Rate: A Practical and Powerful Approach to Multiple Testing. J. R. Stat. Soc. Ser. B Stat. Methodol. 1995, 57, 289-300. [CrossRef]

12. Ponnio, T.; Conneely, O.M. Nor-1 regulates hippocampal axon guidance, pyramidal cell survival, and seizure susceptibility. Mol. Cell. Biol. 2004, 24, 9070-9078. [CrossRef] [PubMed]

13. Bridi, M.S.; Hawk, J.D.; Chatterjee, S.; Safe, S.; Abel, T. Pharmacological Activators of the NR4A Nuclear Receptors Enhance LTP in a CREB/CBP-Dependent Manner. Neuropsychopharmacology 2017, 42, 1243-1253. [CrossRef] [PubMed]

14. Pearen, M.A.; Ryall, J.G.; Maxwell, M.A.; Ohkura, N.; Lynch, G.S.; Muscat, G.E.O. The Orphan Nuclear Receptor, NOR-1, Is a Target of $\beta$-Adrenergic Signaling in Skeletal Muscle. Endocrinology 2006, 147, 5217-5227. [CrossRef]

15. Gao, W.; Fu, Y.; Yu, C.; Wang, S.; Zhang, Y.; Zong, C.; Xu, T.; Liu, Y.; Li, X.; Wang, X. Elevation of NR4A3 expression and its possible role in modulating insulin expression in the pancreatic beta cell. PLoS ONE 2014, 9, e91462. [CrossRef]

16. Delion, S.; Chalon, S.; Guilloteau, D.; Besnard, J.C.; Durand, G. $\alpha$-Linolenic Acid Dietary Deficiency Alters Age-Related Changes of Dopaminergic and Serotoninergic Neurotransmission in the Rat Frontal Cortex. J. Neurochem. 1996, 66, 1582-1591. [CrossRef]

17. Butts, T.; Green, M.J.; Wingate, R.J. Development of the cerebellum: Simple steps to make a "little brain”. Development 2014, 141, 4031-4041. [CrossRef]

18. Buckner Randy, L. The Cerebellum and Cognitive Function: 25 Years of Insight from Anatomy and Neuroimaging. Neuron 2013, 80, 807-815. [CrossRef] 
19. Neville, H.E.; Chase, H.P. Undernutrition and cerebellar development. Exp. Neurol. 1971, 33, 485-497. [CrossRef]

20. Warren, M.A.; Bedi, K.S. The effects of a lengthy period of undernutrition from birth and subsequent nutritional rehabilitation on the granule-to-Purkinje cell ratio in the rat cerebellum. J. Anat. 1988, 159, 147-153.

21. Weisinger, H.S.; Vingrys, A.J.; Sinclair, A.J. Dietary manipulation of long-chain polyunsaturated fatty acids in the retina and brain of guinea pigs. Lipids 1995, 30, 471-473. [CrossRef] [PubMed]

22. Igarashi, M.; Kim, H.-W.; Gao, F.; Chang, L.; Ma, K.; Rapoport, S.I. Fifteen weeks of dietary n-3 polyunsaturated fatty acid deprivation increases turnover of $n-6$ docosapentaenoic acid in rat-brain phospholipids. Biochim. Biophys. Acta 2012, 1821, 1235-1243. [CrossRef] [PubMed]

23. Ntambi, J.M.; Bené, H. Polyunsaturated fatty acid regulation of gene expression. J. Mol. Neurosci. 2001, 16, 273-278. [CrossRef]

24. Kitajka, K.; Sinclair, A.J.; Weisinger, R.S.; Weisinger, H.S.; Mathai, M.; Jayasooriya, A.P.; Halver, J.E.; Puskás, L.G. Effects of dietary omega-3 polyunsaturated fatty acids on brain gene expression. Proc. Natl. Acad. Sci. USA 2004, 101, 10931-10936. [CrossRef] [PubMed]

25. Varga, T.; Czimmerer, Z.; Nagy, L. PPARs are a unique set of fatty acid regulated transcription factors controlling both lipid metabolism and inflammation. Biochim. Biophys. Acta 2011, 1812, 1007-1022. [CrossRef]

26. Kuperstein, F.; Yakubov, E.; Dinerman, P.; Gil, S.; Eylam, R.; Salem, N., Jr. Overexpression of dopamine receptor genes and their products in the postnatal rat brain following maternal n-3 fatty acid dietary deficiency. Overexpression of dopamine receptor genes and their products in the postnatal rat brain following maternal n-3 fatty acid dietary deficiency. J. Neurochem. 2005, 95, 1550-1562.

27. Zimmer, L.; Delion-Vancassel, S.; Durand, G.; Guilloteau, D.; Bodard, S.; Besnard, J.C.; Chalon, S. Modification of dopamine neurotransmission in the nucleus accumbens of rats deficient in $n-3$ polyunsaturated fatty acids. J. Lipid Res. 2000, 41, 32-40.

28. Kitajka, K.; Puskás, L.G.; Zvara, Á.; Hackler, L.; Barceló-Coblijn, G.; Yeo, Y.K.; Farkas, T. The role of n-3 polyunsaturated fatty acids in brain: Modulation of rat brain gene expression by dietary $n-3$ fatty acids. Proc. Natl. Acad. Sci. USA 2002, 99, 2619-2624. [CrossRef]

29. Barceló-Coblijn, G.; Hőgyes, E.; Kitajka, K.; Puskás, L.G.; Zvara, Á.; Hackler, L.; Nyakas, C.; Penke, Z.; Farkas, T. Modification by docosahexaenoic acid of age-induced alterations in gene expression and molecular composition of rat brain phospholipids. Proc. Natl. Acad. Sci. USA 2003, 100, 11321. [CrossRef]

30. Barceló-Coblijn, G.; Kitajka, K.; Puskás, L.G.; Hőgyes, E.; Zvara, A.; Hackler, L., Jr.; Farkas, T. Gene expression and molecular composition of phospholipids in rat brain in relation to dietary $n-6$ to $n-3$ fatty acid ratio. Biochim. Biophys. Acta 2003, 1632, 72-79.

31. Puskás, L.G.; Kitajka, K.; Nyakas, C.; Barcelo-Coblijn, G.; Farkas, T. Short-term administration of omega 3 fatty acids from fish oil results in increased transthyretin transcription in old rat hippocampus. Proc. Natl. Acad. Sci. USA 2003, 100, 1580. [CrossRef] [PubMed]

32. Hurd, P.J.; Nelson, C.J. Advantages of next-generation sequencing versus the microarray in epigenetic research. Brief. Funct. Genom. 2009, 8, 174-183. [CrossRef] [PubMed]

33. Liu, H.; Bebu, I.; Li, X. Microarray probes and probe sets. Front. Biosci. (Elite Ed) 2010, 2, 325-338. [CrossRef] [PubMed]

34. Workman, A.D.; Charvet, C.J.; Clancy, B.; Darlington, R.B.; Finlay, B.L. Modeling Transformations of Neurodevelopmental Sequences across Mammalian Species. J. Neurosci. 2013, 33, 7368. [CrossRef]

35. Picklo, M.J., Sr.; Johnson, L.; Idso, J. PPAR mRNA Levels Are Modified by Dietary n-3 Fatty Acid Restriction and Energy Restriction in the Brain and Liver of Growing Rats. J. Nutr. 2017, 147, 161-169. [CrossRef] [PubMed]

36. Reeves, P.G. Components of the AIN-93 diets as improvements in the AIN-76A diet. J. Nutr. 1997, 127, 838s-841s. [CrossRef] [PubMed]

37. Picklo, M.J.; Thyfault, J.P. Vitamin E and vitamin C do not reduce insulin sensitivity but inhibit mitochondrial protein expression in exercising obese rats. Appl. Physiol. Nutr. Metab. 2015, 40, 343-352. [CrossRef] 
38. Mehus, A.A.; Picklo, S.M.J. Brain and Hepatic Mt mRNA Is Reduced in Response to Mild Energy Restriction and n-3 Polyunsaturated Fatty Acid Deficiency in Juvenile Rats. Nutrients 2017, 9, 1145. [CrossRef]

39. Dobin, A.; Davis, C.A.; Schlesinger, F.; Drenkow, J.; Zaleski, C.; Jha, S.; Batut, P.; Chaisson, M.; Gingeras, T.R. STAR: Ultrafast universal RNA-seq aligner. Bioinformatics 2013, 29, 15-21. [CrossRef]

40. Trapnell, C.; Williams, B.A.; Pertea, G.; Mortazavi, A.; Kwan, G.; van Baren, M.J.; Salzberg, S.L.; Wold, B.J.; Pachter, L. Transcript assembly and quantification by RNA-Seq reveals unannotated transcripts and isoform switching during cell differentiation. Nat. Biotechnol. 2010, 28, 511-515. [CrossRef]

41. Lawrence, M.; Huber, W.; Pages, H.; Aboyoun, P.; Carlson, M.; Gentleman, R.; Morgan, M.T.; Carey, V.J. Software for computing and annotating genomic ranges. PLoS Comput. Biol. 2013, 9, e1003118. [CrossRef] [PubMed]

42. Bullard, J.H.; Purdom, E.; Hansen, K.D.; Dudoit, S. Evaluation of statistical methods for normalization and differential expression in mRNA-Seq experiments. BMC Bioinform. 2010, 11, 94. [CrossRef] [PubMed]

43. Wagner, G.P.; Kin, K.; Lynch, V.J. Measurement of mRNA abundance using RNA-seq data: RPKM measure is inconsistent among samples. Theory Biosci. 2012, 131, 281-285. [CrossRef] [PubMed]

44. Picklo, M.J.; Murphy, E.J. A High-Fat, High-Oleic Diet, But Not a High-Fat, Saturated Diet, Reduces Hepatic $\alpha$-Linolenic Acid and Eicosapentaenoic Acid Content in Mice. Lipids 2016, 51, 537-547. [CrossRef] [PubMed]

45. Hara, A.; Radin, N.S. Lipid extraction of tissues with a low-toxicity solvent. Anal. Biochem. 1978, 90, 420-426. [CrossRef]

46. Prado, E.L.; Dewey, K.G. Nutrition and brain development in early life. Nutr. Rev. 2014, 72, $267-284$. [CrossRef] [PubMed]

47. Kothapalli, K.S.D.; Anthony, J.C.; Pan, B.S.; Hsieh, A.T.; Nathanielsz, P.W.; Brenna, J.T. Differential Cerebral Cortex Transcriptomes of Baboon Neonates Consuming Moderate and High Docosahexaenoic Acid Formulas. PLoS ONE 2007, 2, e370. [CrossRef]

48. Hammamieh, R.; Chakraborty, N.; Gautam, A.; Miller, S.-A.; Muhie, S.; Meyerhoff, J.; Jett, M. Transcriptomic Analysis of the Effects of a Fish Oil Enriched Diet on Murine Brains. PLoS ONE 2014, 9, e90425. [CrossRef]

49. Szostak, A.; Ogłuszka, M.; te Pas, M.F.W.; Poławska, E.; Urbański, P.; Juszczuk-Kubiak, E.; Blicharski, T.; Pareek, C.S.; Dunkelberger, J.R.; Horbańczuk, J.O.; et al. Effect of a diet enriched with omega-6 and omega-3 fatty acids on the pig liver transcriptome. Genes Nutr. 2016, 11, 9. [CrossRef]

50. Paulsen, R.F.; Granas, K.; Johnsen, H.; Rolseth, V.; Sterri, S. Three related brain nuclear receptors, NGFI-B, Nurr1, and NOR-1, as transcriptional activators. J. Mol. Neurosci. 1995, 6, 249-255. [CrossRef]

51. Ohkura, N.; Hijikuro, M.; Yamamoto, A.; Miki, K. Molecular cloning of a novel thyroid/steroid receptor superfamily gene from cultured rat neuronal cells. Biochem. Biophys. Res. Commun. 1994, 205, 1959-1965. [CrossRef] [PubMed]

52. Fu, Y.; Luo, L.; Luo, N.; Zhu, X.; Garvey, W.T. NR4A orphan nuclear receptors modulate insulin action and the glucose transport system: Potential role in insulin resistance. J. Biol. Chem. 2007, 282, 31525-31533. [CrossRef] [PubMed]

53. Volakakis, N.; Kadkhodaei, B.; Joodmardi, E.; Wallis, K.; Panman, L.; Silvaggi, J.; Spiegelman, B.M.; Perlmann, T. NR4A orphan nuclear receptors as mediators of CREB-dependent neuroprotection. Proc. Natl. Acad. Sci. USA 2010, 107, 12317. [CrossRef] [PubMed]

54. Hawk, J.D.; Bookout, A.L.; Poplawski, S.G.; Bridi, M.; Rao, A.J.; Sulewski, M.E.; Kroener, B.T.; Manglesdorf, D.J.; Abel, T. NR4A nuclear receptors support memory enhancement by histone deacetylase inhibitors. J. Clin. Investig. 2012, 122, 3593-3602. [CrossRef] [PubMed]

55. Pearen, M.A.; Myers, S.A.; Raichur, S.; Ryall, J.G.; Lynch, G.S.; Muscat, G.E.O. The Orphan Nuclear Receptor, NOR-1, a Target of $\beta$-Adrenergic Signaling, Regulates Gene Expression that Controls Oxidative Metabolism in Skeletal Muscle. Endocrinology 2008, 149, 2853-2865. [CrossRef] [PubMed]

56. Chalon, S.; Delion-Vancassel, S.; Belzung, C.; Guilloteau, D.; Leguisquet, A.-M.; Besnard, J.-C.; Durand, G. Dietary Fish Oil Affects Monoaminergic Neurotransmission and Behavior in Rats. J. Nutr. 1998, 128, 2512-2519. [CrossRef] [PubMed] 
57. DeMar, J.C., Jr.; Ma, K.; Bell, J.M.; Rapoport, S.I. Half-lives of docosahexaenoic acid in rat brain phospholipids are prolonged by 15 weeks of nutritional deprivation of $n-3$ polyunsaturated fatty acids. J. Neurochem. 2004, 91, 1125-1137. [CrossRef]

58. Kim, H.-W.; Rao, J.S.; Rapoport, S.I.; Igarashi, M. Regulation of rat brain polyunsaturated fatty acid (PUFA) metabolism during graded dietary n-3 PUFA deprivation. Prostaglandins Leukot. Essent. Fatty Acids 2011, 85, 361-368. [CrossRef]

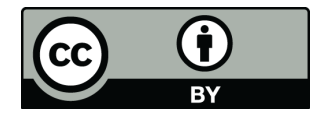

(C) 2019 by the authors. Licensee MDPI, Basel, Switzerland. This article is an open access article distributed under the terms and conditions of the Creative Commons Attribution (CC BY) license (http://creativecommons.org/licenses/by/4.0/). 